\title{
A Pharmacokinetic Bioequivalence Study Comparing Pirfenidone Tablet and Capsule Dosage Forms in Healthy Adult Volunteers
}

Lin Pan · Paula Belloni · Han Ting Ding · Jianshuang Wang •

Christopher M. Rubino · Wendy S. Putnam

Received: June 12, 2017 / Published online: August 14, 2017

(C) The Authors 2017. This article is an open access publication

\section{ABSTRACT}

Introduction: Pirfenidone film-coated tablets were developed to offer an alternative to the marketed capsule formulation. This study assessed the bioequivalence of the tablet and capsule formulations under fed and fasted states.

Methods: A Phase I, open-label, randomized, four-treatment-period, four-sequence, crossover pharmacokinetics study (NCT02525484) was conducted. Each subject received an 801-mg single dose of pirfenidone as three 267-mg

Enhanced content To view enhanced content for this article go to http://www.medengine.com/Redeem/ B3E8F0606C5B1C8F.

Electronic supplementary material The online version of this article (doi:10.1007/s12325-017-0594-8) contains supplementary material, which is available to authorized users.

L. Pan $(\varangle)$ · P. Belloni · H. T. Ding · J. Wang ·

W. S. Putnam

Genentech Inc., 1 DNA way, South San Francisco,

CA 94080-4990, USA

e-mail: pan.lin@gene.com

C. M. Rubino

Institute for Clinical Pharmacodynamics,

Schenectady, NY, USA

C. M. Rubino

University at Buffalo, Amherst, NY, USA capsules or one 801-mg tablet under fasted and fed conditions. Pirfenidone plasma $C_{\max }$ $\mathrm{AUC}_{0-\mathrm{t}}$ and $\mathrm{AUC}_{0-\infty}$ were used to assess bioequivalence.

Results: Forty-four subjects were randomized to treatment. The 801-mg tablet in the fasted state met bioequivalence criteria [90\% confidence intervals (CI) 80.00-125.00\%] for the GLSM ratios of natural $\log$-transformed $C_{\max }$, $\mathrm{AUC}_{0-\mathrm{t}}$ and $\mathrm{AUC}_{0-\infty}$. Under fed conditions, the 801-mg tablet met the bioequivalence criteria for $\mathrm{AUC}_{0-\mathrm{t}}$ and $\mathrm{AUC}_{0-\infty}$, but slightly exceeded the bioequivalence criteria for the $C_{\max }(90 \% \mathrm{CI}$ of $108.26-125.60 \%)$. The tablet $C_{\max }$ was approximately $17 \%$ higher than that of the capsules. In the fed state, the tablet $C_{\max }$, and both $\mathrm{AUC}_{0-\mathrm{t}}$ and $\mathrm{AUC}_{0-\infty}$ were reduced by $39 \%$ and $17 \%$, respectively, relative to the fasted state. The tablet and capsules had acceptable tolerability profiles.

Conclusions: The pirfenidone 801-mg tablet met bioequivalence criteria when compared with three 267-mg capsules in the fasted state. The tablet $C_{\max }$ was slightly higher relative to capsules in the fed state, but this is not expected to have a clinically meaningful impact on the benefit-risk profile of pirfenidone.

Funding: This work was supported by F. Hoffmann-La Roche Ltd.

Keywords: Bioequivalence; Idiopathic pulmonary fibrosis; Pharmacokinetics; Pirfenidone; Respiratory 


\section{INTRODUCTION}

Idiopathic pulmonary fibrosis (IPF) is a debilitating, progressive and fatal lung disease [1-3]. Pirfenidone (as a 267-mg capsule) is approved by the European Medicines Agency (EMA) and the US Food and Drug Administration (FDA), and is recommended in international treatment guidelines for the treatment of IPF in the majority of patients $[2,4,5]$.

Although the mechanism of action has not been fully established, pirfenidone is an antifibrotic agent that affects multiple biological pathways in vivo. Pirfenidone attenuates fibroblast proliferation and production of fibrosis-associated proteins and cytokines, and decreases biosynthesis and accumulation of extracellular matrix in response to cytokine growth factors [6-8].

Clinical studies in patients with IPF have shown that pirfenidone reduced the decline in forced vital capacity and the risk of all-cause mortality versus placebo at 1 year $[9,10]$. Pirfenidone is generally well tolerated; however, gastrointestinal and skin-related adverse events (AEs) can affect tolerability in some patients, particularly within the first 6 months of treatment $[11,12]$.

Clinical pharmacokinetic (PK) studies have demonstrated that, after oral administration of pirfenidone in various oral formulations, peak plasma pirfenidone concentration $\left(C_{\max }\right)$ and area under the plasma concentration versus time curve (AUC) are significantly higher in a fasted versus a fed state [13-15]. The observed reduction in $C_{\max }$ in the fed state is of clinical benefit as pirfenidone-related side effects were associated with $C_{\max }[14,15]$. Therefore, prescribing information recommends taking pirfenidone with food $[4,5]$.

Gradual dose titration on initiation of pirfenidone can help with the management of AEs and prevent treatment discontinuation $[11,12]$. Currently, the pirfenidone capsule is available as a $267-\mathrm{mg}$ capsule and the flexibility offered by the capsule formulation is key to facilitating tailored dosing until patients are established on a stable dose of pirfenidone. The recommended starting dose is $1 \times 267-\mathrm{mg}$ capsule three times daily (tid) for 1 week, followed by $2 \times 267-m g$ capsules tid for 1 week, followed by the maintenance dosage of $3 \times 267-\mathrm{mg}$ capsules tid $[5,11]$. If AEs occur during pirfenidone treatment, temporary dose reduction followed by re-escalation can help to resolve AEs [11].

Once patients are on a stable maintenance dose of $2403 \mathrm{mg} /$ day, they may benefit from having fewer pills to take daily. This could improve medication adherence, which is defined as the degree to which patients follow recommendations on the timing, dosage and frequency of their medications [16]. Poor adherence may be associated with worse health outcomes [17-20] and the prescribed number of dose units of medication daily may be an important factor in influencing adherence, with an increasing number of doses associated with poorer adherence [20-22].

Pirfenidone film-coated 801-mg tablets were developed to provide patients who are tolerating the recommended daily maintenance dose with an alternative to the $267-\mathrm{mg}$ capsule formation. The reduced pill burden of taking $1 \times 801-\mathrm{mg}$ tablet tid has the potential to increase adherence in these patients.

The aim of this study was to assess the bioequivalence of pirfenidone after a single-dose oral administration of $1 \times 801-\mathrm{mg}$ tablet compared with a single-dose of $3 \times 267-\mathrm{mg}$ capsules under fasted and fed states.

\section{METHODS}

\section{Study Design}

This single-dose, Phase I, open-label, randomized, four-treatment-period, four-sequence, crossover PK study (NCT02525484) was designed to determine the bioequivalence of pirfenidone when administered via a tablet versus a capsule formulation in the fed and fasted states (Fig. 1).

Following a screening period of up to 28 days, healthy volunteers aged $18-55$ years were randomized to one of four treatment sequences, during which the following treatments were administered as single oral doses 


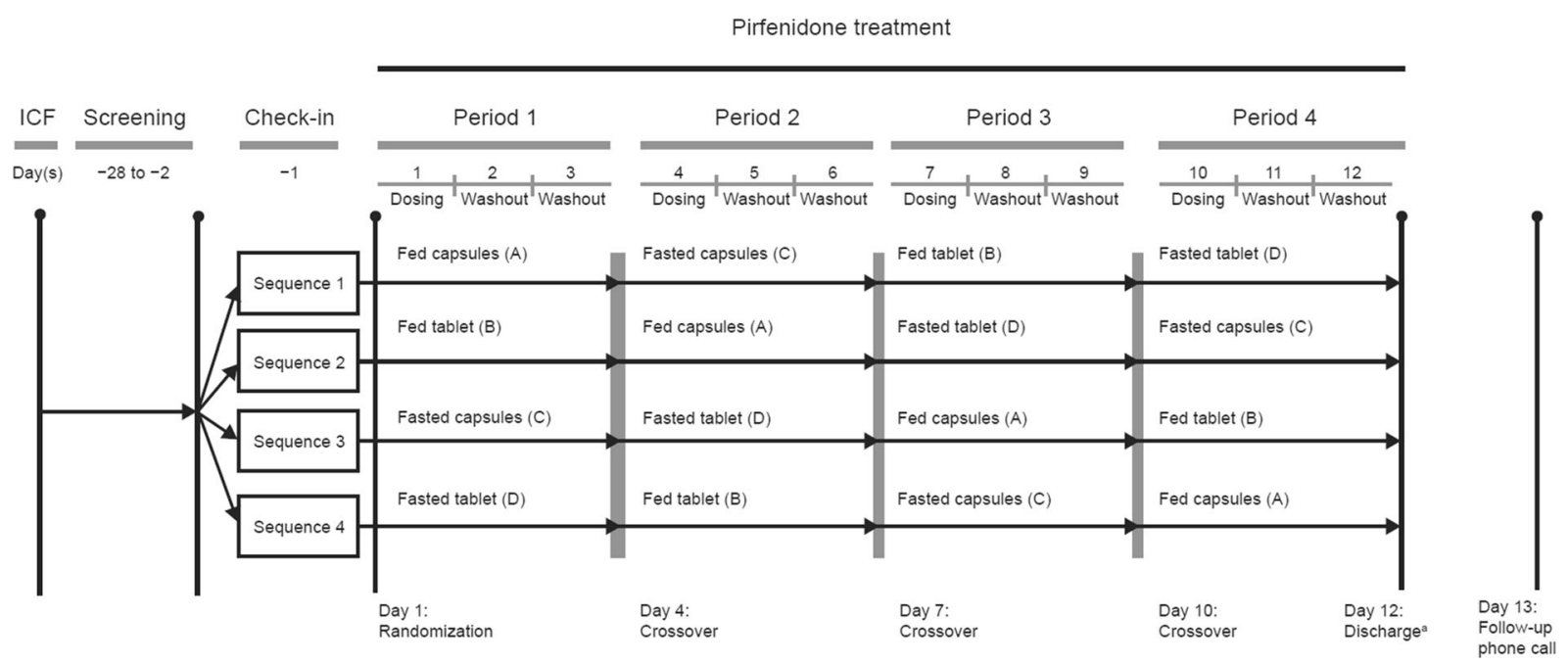

Fig. 1 Study design. $I C F$ informed consent, $P K$ pharmacokinetic ${ }^{a}$ Discharge after completion of PK blood draws and assessments

(i.e. there was no dose titration as is normally used in patients with IPF; Fig. 1):

- Treatment A = pirfenidone $3 \times 267-\mathrm{mg}$ capsules in the fed state.

- Treatment $\mathrm{B}=$ pirfenidone $1 \times 801-\mathrm{mg}$ tablet in the fed state.

- Treatment $\mathrm{C}=$ pirfenidone $3 \times 267-\mathrm{mg}$ capsules in the fasted state.

- Treatment $\mathrm{D}=$ pirfenidone $1 \times 801-\mathrm{mg}$ tablet in the fasted state.

Knowledge of the dosage form (i.e. tablet or capsule) would not influence the PK assessment; hence, the study was not blinded to simplify the study conduct. However, persons involved in analyzing the PK data were blinded as to whether the sample was following tablet or capsule administration until the PK parameters were determined. A $4 \times 4$ Williams study design was used, with the four possible treatment sequences being ACBD, BADC, CDAB and DBCA (Fig. 1). Subjects remained at the clinic for 12 nights, from the day before the first dose of the study drug until $48 \mathrm{~h}$ after the last dose of the study drug following completion of safety assessments. Study drug was administered on Days 1, 4, 7 and 10 , with a 72 -h washout period between the administration of doses to ensure sufficient washout based on a half-life of 2-3 h (Fig. 1).

Under fed conditions, pirfenidone was administered after a high-fat and high-calorie meal, consumed after an overnight fast as per guidance from global regulatory agencies $[23,24]$. Each high-fat breakfast consisted of approximately 840 calories, provided from $32 \mathrm{~g}$ of protein, $54 \mathrm{~g}$ of fat, and $57 \mathrm{~g}$ of carbohydrate. A typical breakfast included two fried eggs, two strips of bacon, two slices of toast, two pats of butter, four ounces of hash brown potatoes, and eight fluid ounces of whole milk. Under fasting conditions, pirfenidone was administered after an overnight fast of at least 10 consecutive hours.

To be eligible for participation in the study, subjects were required to be non-smokers, in good health, and with no significant medical history (in the opinion of the investigator). Participants also agreed to abstain from alcohol, caffeine, cruciferous vegetables and strenuous exercise for the duration of the study. The study was conducted in accordance with the International Conference on Harmonisation Guidelines, the Declaration of Helsinki and relevant local legal and regulatory requirements. Written informed consent was obtained from each subject before any study procedures were performed.

\section{Sample Collection}

Blood samples $(4 \mathrm{~mL})$ for the harvesting of plasma to determine plasma pirfenidone concentrations and PK calculations were drawn in EDTA vacutainer tubes on Days 1, 4, 7 and 10: 
Table 1 Summary of subject demographics at baseline

\begin{tabular}{|c|c|c|c|c|c|}
\hline & \multicolumn{5}{|c|}{ Treatment sequence ${ }^{a}$} \\
\hline & $\operatorname{ACBD} n=11$ & BADC $n=11$ & $\mathrm{CDAB} n=11$ & DBCA $n=11$ & Total $n=44$ \\
\hline Median (min, max) age, years & $33.0(20,53)$ & $28.0(21,49)$ & $41.0(25,54)$ & $38.0(20,50)$ & $33.0(20,54)$ \\
\hline Male, $n(\%)$ & $5(45.5)$ & $8(72.7)$ & $9(81.8)$ & $6(54.5)$ & $28(63.6)$ \\
\hline \multicolumn{6}{|l|}{ Race, $n(\%)$} \\
\hline White & $6(54.5)$ & $6(54.5)$ & $5(45.5)$ & $7(63.6)$ & $24(54.5)$ \\
\hline Black or African American & $5(45.5)$ & $5(45.5)$ & $4(36.4)$ & $3(27.3)$ & $17(38.6)$ \\
\hline Other & 0 & 0 & $2(18.2)$ & $1(9.1)$ & $3(6.8)$ \\
\hline Mean (SD) weight (kg) & $73.9(13.0)$ & $71.2(13.4)$ & $85.3(14.1)$ & $77.8(11.0)$ & $77.0(13.6)$ \\
\hline Mean (SD) height $(\mathrm{cm})$ & $168.6(7.1)$ & $168.8(8.4)$ & $177.4(11.4)$ & $170.0(10.3)$ & $171.2(9.8)$ \\
\hline Mean (SD) BMI $\left(\mathrm{kg} / \mathrm{m}^{2}\right)$ & $25.9(3.3)$ & $24.9(3.7)$ & $26.9(2.3)$ & $26.9(2.9)$ & $26.1(3.1)$ \\
\hline
\end{tabular}

$B M I$ body mass index, $S D$ standard deviation

a Treatment A $=3 \times 267-\mathrm{mg}$ capsules in the fed state; treatment $\mathrm{B}=1 \times 801-\mathrm{mg}$ tablet in the fed state; treatment $\mathrm{C}=3 \times 267-\mathrm{mg}$ capsules in the fasted state; treatment $\mathrm{D}=1 \times 801-\mathrm{mg}$ tablet in the fasted state

Table 2 PK parameters of pirfenidone following single-dose administration in the fed and fasted states

\begin{tabular}{|c|c|c|c|c|}
\hline \multirow[t]{3}{*}{ PK parameter } & \multicolumn{4}{|l|}{ Geometric mean (CV\%) } \\
\hline & \multicolumn{2}{|l|}{ Fed state $(n=43)$} & \multicolumn{2}{|l|}{ Fasted state $(n=42)$} \\
\hline & $3 \times 267-\mathrm{mg}$ capsules & $1 \times 801-\mathrm{mg}$ tablet & $3 \times 267-\mathrm{mg}$ capsules & $1 \times 801-\mathrm{mg}$ tablet \\
\hline$C_{\max }(\mathrm{ng} / \mathrm{mL})$ & $6560(25.5)$ & $7640(27.9)$ & $12,500(27.9)$ & $12,600(32.8)$ \\
\hline $\mathrm{AUC}_{0-\mathrm{t}}(\mathrm{ng} \mathrm{h} / \mathrm{mL})$ & $39,500(36.6)$ & $40,600(35.0)$ & $49,500(34.5)$ & $49,200(35.1)$ \\
\hline $\mathrm{AUC}_{0-\infty}(\mathrm{ng} \mathrm{h} / \mathrm{mL})$ & $39,800(37.0)$ & $40,900(35.5)$ & $49,700(34.9)$ & $49,400(35.5)$ \\
\hline$t_{\max }(\mathrm{h})^{\mathrm{a}}$ & $3.00(0.50,6.00)$ & $2.05(1.00,6.00)$ & $0.75(0.25,2.00)$ & $1.00(0.25,3.00)$ \\
\hline$t_{1 / 2}(\mathrm{~h})$ & $2.75(0.585)$ & $2.74(0.579)$ & $2.77(0.589)$ & $2.77(0.571)$ \\
\hline
\end{tabular}

$A U C_{O-\infty}$ area under the plasma concentration versus time curve from time zero to infinity, $A U C_{O-t}$ area under the plasma concentration versus time curve from time zero to the time of the last quantifiable concentration, $C_{\text {max }}$ peak plasma concentration, $C V$ coefficient of variation, $P K$ pharmacokinetic, $t_{1 / 2}$ terminal elimination half-life, $t_{\max }$ time to peak plasma concentration

a Median (minimum, maximum)

up to $3 \mathrm{~h}$ pre-dose and $0.25,0.5,1,1.5,2,3,4,6$, $8,10,12,16$ and $24 \mathrm{~h}$ post-dose.

\section{Bioanalytical Methods}

A validated liquid chromatography tandem mass spectrometric (LC-MS/MS) method was used to determine the concentration of pirfenidone in $\mathrm{K}_{2}$ EDTA-treated plasma samples. Pirfenidone and the deuterium-labeled internal standard, pirfenidone-d5, were extracted from plasma, by means of supported liquid extraction. The LC-MS/MS analysis was carried out with a Phenomenex (Torrance, CA, USA) 
Gemini ${ }^{\circledR}$ C18 column on a Shimadzu (Kyoto, Japan) Prominence ${ }^{\circledR}$ HPLC system coupled with a Sciex (Framingham, MA, USA) API $4000^{\mathrm{TM}}$ triple quadrupole mass spectrometer. Pirfenidone concentrations were calculated using a $1 / x^{2}$ weighted linear regression over a range from 5.00 to $3000 \mathrm{ng} / \mathrm{mL}$. This method offered acceptable accuracy and precision. Validation methods confirmed that study samples with a pirfenidone concentration above $3000 \mathrm{ng} / \mathrm{mL}$ could be measured following dilution, with a dilution quality control sample of $50,000 \mathrm{ng} /$ $\mathrm{mL}$ accurately measured after a 100-fold dilution with blank human plasma. There was no evidence of carryover that could adversely affect the quantitation of pirfenidone.

\section{PK and Bioequivalence Analyses}

Primary PK parameters in this study included the observed maximum plasma concentration $\left(C_{\text {max }}\right)$, area under the plasma concentration versus time curve from time zero to the time of the last quantifiable concentration $\left(\mathrm{AUC}_{0-\mathrm{t}}\right)$ and AUC from zero extrapolated to infinity $\left(\mathrm{AUC}_{0-\infty}.\right)$. Secondary PK parameters included observed time to reach peak concentration $\left(t_{\max }\right)$, and elimination half-life $\left(\mathrm{t}_{1 / 2}\right)$. PK parameters for pirfenidone were estimated from individual plasma concentration versus time profiles using a non-compartmental approach with Phoenix ${ }^{\circledR}$ WinNonlin ${ }^{\circledR} 6.3$ (Certara USA, St. Louis, MO, USA).

Bioequivalence between the test treatment $(1 \times 801$-mg pirfenidone tablet $)$ and the reference treatment $(3 \times 267-\mathrm{mg}$ pirfenidone capsules) was assessed by calculating two-sided $90 \%$ confidence intervals (CIs) for the geometric least-squares means (GLSM) ratio between the two treatments for both the fed and fasted states. An analysis of variance (ANOVA) was performed on the natural log-transformed primary PK measurements: $C_{\max }, \mathrm{AUC}_{0-\mathrm{t}}$ and $\mathrm{AUC}_{0-\infty}$. The $90 \%$ CIs of the GLSM ratio of the test treatment to the reference treatment were calculated by taking the anti-log of the corresponding 90\% CIs for the differences between the means on the log scale. Bioequivalence was established if the $90 \%$ CI for the ratio was
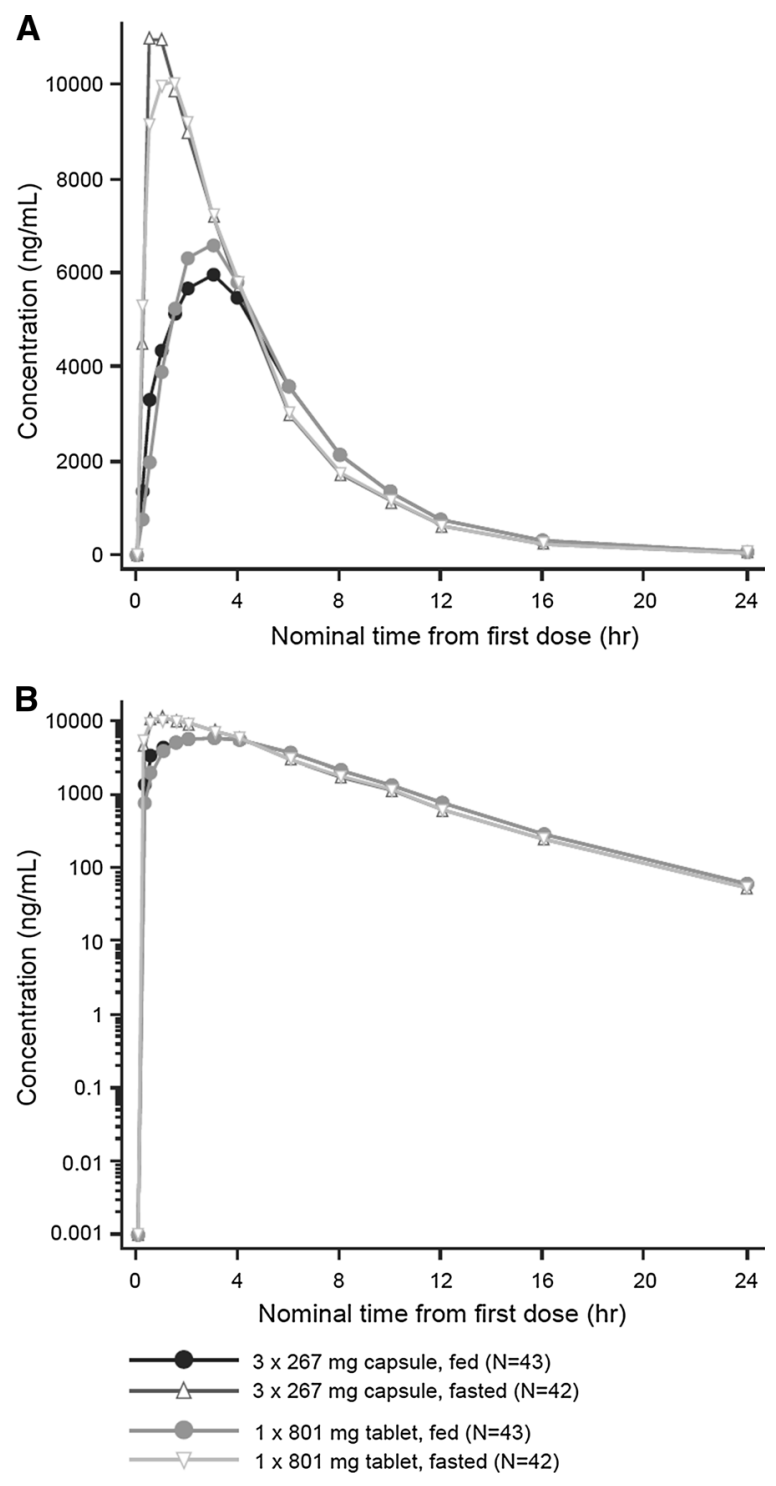

Fig. 2 Mean plasma concentration ${ }^{a}$ versus time profiles with a linear and $\mathbf{b}$ semi-logarithmic scales. Plasma concentration values below limit of quantitation (BLOQ) were set to zero except when a BLOQ fell between two quantifiable values, in which case it was treated as missing data. One subject who was fasted and fed and one subject who was fasted only were excluded from descriptive statistics calculations because of vomiting within $6 \mathrm{~h}$ of dosing ${ }^{a}$ Mean concentration calculated from individual plasma concentration at the same time point

within bioequivalence limits of $80.00 \%$ to $125.00 \%$ [23, 24].

Power calculations indicated that a total of 36 subjects would provide $85 \%$ power to 
Table 3 Statistical assessment of bioequivalence comparing pirfenidone $3 \times 267$-mg capsules and $1 \times 801$-mg tablet in the fed and fasted states

\begin{tabular}{|c|c|c|}
\hline \multirow{2}{*}{ PK parameter } & \multicolumn{2}{|c|}{ Tablet vs. capsules, \% GLSM ratio $(90 \% \mathrm{CI})$} \\
\hline & Fed state $(n=43)$ & Fasted state $(n=42)$ \\
\hline$C_{\max }(\mathrm{ng} / \mathrm{mL})$ & $116.61(108.26,125.60)$ & $101.26(94.41,108.60)$ \\
\hline $\mathrm{AUC}_{0-\mathrm{t}}(\mathrm{ng} \mathrm{h} / \mathrm{mL})$ & $103.06(99.55,106.69)$ & $99.63(96.66,102.69)$ \\
\hline $\operatorname{AUC}_{0-\infty}(\mathrm{ng} \mathrm{h} / \mathrm{mL})$ & $103.05(99.54,106.69)$ & $99.61(96.64,102.68)$ \\
\hline
\end{tabular}

$A U C_{0-\infty}$ area under the plasma concentration versus time curve from time zero to infinity, $A U C_{0-t}$ area under the plasma concentration versus time curve from time zero to the time of the last quantifiable concentration, $C I$ confidence interval, $C_{\max }$ peak plasma concentration, GLSM geometric least-squares mean, $P K$ pharmacokinetic

Table 4 Statistical assessment of bioequivalence comparing pirfenidone $1 \times 801-\mathrm{mg}$ tablet in the fed and fasted states

\begin{tabular}{ll}
\hline PK parameter & $\begin{array}{l}\text { Fed }^{\text {a }} \text { vs. fasted } \\
\text { ratio }(\mathbf{9 0 \%} \text { CI })\end{array}$ \\
\hline$C_{\max }(\mathrm{ng} / \mathrm{mL})$ & $60.54(55.82,65.67)$ \\
$\mathrm{AUC}_{0-\mathrm{t}}(\mathrm{ng} \mathrm{h} / \mathrm{mL})$ & $82.56(80.03,85.17)$ \\
$\mathrm{AUC}_{0-\infty}(\mathrm{ng} \mathrm{h} / \mathrm{mL})$ & $82.68(80.14,85.29)$ \\
\hline
\end{tabular}

$A U C_{0-\infty}$ area under the plasma concentration versus time curve from time zero to infinity, $A U C_{0-t}$ area under the plasma concentration versus time curve from time zero to the time of the last quantifiable concentration, $C I$ confidence interval, $C_{\max }$ peak plasma concentration, GLSM geometric least-squares mean, $P K$ pharmacokinetic

a $n=43$

b $n=42$

conclude bioequivalence if the true ratio between the pirfenidone capsule and tablet was 0.95 to 1.05 and the intra-subject coefficient of variation was 0.26 . The intra-subject coefficient of variation value was selected based on the largest value reported in a previous PK study of the pirfenidone capsule formulation [14]. To ensure that at least 36 subjects would complete all study periods with adequate PK data, 44 subjects were enrolled in the study.

\section{Safety Evaluation}

All AEs (including those leading to treatment discontinuation and of special interest) that occurred on or after the first dose of study medication were recorded using Medical Dictionary for Regulatory Activities Version 18.0 and listed by dosing condition. Changes from baseline in laboratory parameters and vital signs were also recorded [please refer to the online supplement for details]. A graphical examination of the exposure-response relationship was conducted to explore a potential relationship between drug exposure and the occurrence of AEs.

\section{RESULTS}

\section{Subjects}

Of 97 subjects screened for inclusion, a total of 44 subjects were randomized to one of the four treatment sequences (Fig. 1). All subjects completed treatment and had blood samples collected at a minimum of 10 time points per treatment period, with at least one sample $\geq 16 \mathrm{~h}$ post-dose. One subject was excluded from the PK analysis for all treatments due to emesis following administration of pirfenidone $1 \times 801-\mathrm{mg}$ tablet in the fed state and pirfenidone $3 \times 267-\mathrm{mg}$ capsules in the fasted state. Another subject experienced emesis following administration of pirfenidone $1 \times 801-\mathrm{mg}$ tablet in the fasted state and was excluded from the PK analyses in the fasted state. Therefore, a total of 43 subjects were included in the PK population in the fed state, and 42 subjects were included in the PK population in the fasted state. All 44 subjects were included in the safety population. Subject demographics are presented in Table 1. 
Table 5 Adverse events

\begin{tabular}{|c|c|c|c|c|c|}
\hline \multirow[t]{2}{*}{$n(\%)$} & \multicolumn{2}{|l|}{ Fed state } & \multicolumn{2}{|l|}{ Fasting state } & \multirow[t]{2}{*}{ Total $^{a}$} \\
\hline & $\begin{array}{l}3 \times 267-\mathrm{mg} \\
\text { capsules } n=44\end{array}$ & $\begin{array}{l}1 \times 801-\mathrm{mg} \\
\text { tablet } n=44\end{array}$ & $\begin{array}{l}3 \times 267-\mathrm{mg} \\
\text { capsules } n=44\end{array}$ & $\begin{array}{l}1 \times 801-\mathrm{mg} \\
\text { tablet } n=44\end{array}$ & \\
\hline Nausea & 0 & $3(6.8)$ & $8(18.2)$ & $10(22.7)$ & $13(29.5)$ \\
\hline Dizziness & 0 & $1(2.3)$ & $4(9.1)$ & $6(13.6)$ & $8(18.2)$ \\
\hline Headache & 0 & $2(4.5)$ & $2(4.5)$ & $3(6.8)$ & $4(9.1)$ \\
\hline Constipation & 0 & $3(6.8)$ & 0 & $1(2.3)$ & $4(9.1)$ \\
\hline Vomiting & 0 & $1(2.3)$ & $1(2.3)$ & $1(2.3)$ & $2(4.5)$ \\
\hline Dyspepsia & 0 & 0 & $1(2.3)$ & $1(2.3)$ & $2(4.5)$ \\
\hline Oral paresthesia & 0 & 0 & $1(2.3)$ & 0 & $1(2.3)$ \\
\hline Pollakiuria & 0 & $1(2.3)$ & 0 & 0 & $1(2.3)$ \\
\hline Vulvovaginal pruritus & 0 & 0 & 0 & $1(2.3)$ & $1(2.3)$ \\
\hline Hot flush & $1(2.3)$ & 0 & 0 & 0 & $1(2.3)$ \\
\hline
\end{tabular}

a Total counts are provided for the entire study with each subject counted only once

\section{PK Analyses}

In the fasted state, pirfenidone $\mathrm{PK}$, measured using the geometric mean $\mathrm{AUC}_{0-\mathrm{t}}, \mathrm{AUC}_{0-\infty}$, and $C_{\max }$, was similar between the tablet and capsules (Table 2). Mean pirfenidone plasma concentration-time profiles stratified by treatment are presented in Fig. 2 . Median $t_{\max }$ were similar between the tablet and capsules (Table 2).

In the fed state, pirfenidone $\mathrm{PK}$, as measured using the geometric mean $\mathrm{AUC}_{0-\mathrm{t}}$ and $\mathrm{AUC}_{0-\infty}$, was similar between the pirfenidone $1 \times 801$-mg tablet and the pirfenidone $3 \times 267-\mathrm{mg}$ capsules (Table 2). The geometric mean $C_{\max }$ for the pirfenidone tablet was approximately $17 \%$ higher compared with the capsules [geometric mean (\% coefficient of variation) $=7640$ (27.9) vs. 6560 (25.5) $\mathrm{ng} / \mathrm{mL}$, respectively) (Table 2 ). Median $t_{\max }$ was approximately $1 \mathrm{~h}$ shorter with the tablet than the capsules [median (min, $\max )=2.05(1.00,6.00)$ vs. $3.00(0.50,6.00) h$, respectively] (Table 2 ).

\section{Bioequivalence Analysis}

Under the fasted state, standard bioequivalence criteria were met for the GLSM ratios of natural log-transformed $C_{\max }, \mathrm{AUC}_{0-\mathrm{t}}$ and $\mathrm{AUC}_{0-\infty}$ for the pirfenidone $1 \times 801-\mathrm{mg}$ tablet (Table 3 ). In the fed state, the $90 \%$ CI values for the GLSM ratios of natural log-transformed $\mathrm{AUC}_{0-\mathrm{t}}$ and $\mathrm{AUC}_{0-\infty}$ met standard bioequivalence criteria (Table 3). The upper CI value for the natural log-transformed $C_{\max }$ for the tablet slightly exceeded the standard bioequivalence criteria (by $0.6 \%$ ), with a value of $125.60 \%$ compared with capsules (Table 3).

\section{Food Effect}

Following administration of the pirfenidone $1 \times 801-\mathrm{mg}$ tablet, pirfenidone $\mathrm{PK}$, as measured by $\mathrm{AUC}_{0-\mathrm{t}}$ and $\mathrm{AUC}_{0-\infty}$, was approximately $17 \%$ lower in the fed state compared with the fasted state, with $90 \%$ CI values of $80.03-85.17 \%$ and $80.14-85.29 \%$, respectively (Table 4). Following administration of the tablet, $C_{\max }$ values were approximately $39 \%$ lower in the fed state compared with the fasted state, with $90 \%$ CI values of $55.82-65.67 \%$ (Table 4 ). The effect of food on pirfenidone PK was consistent between the tablet and capsule formulations. 

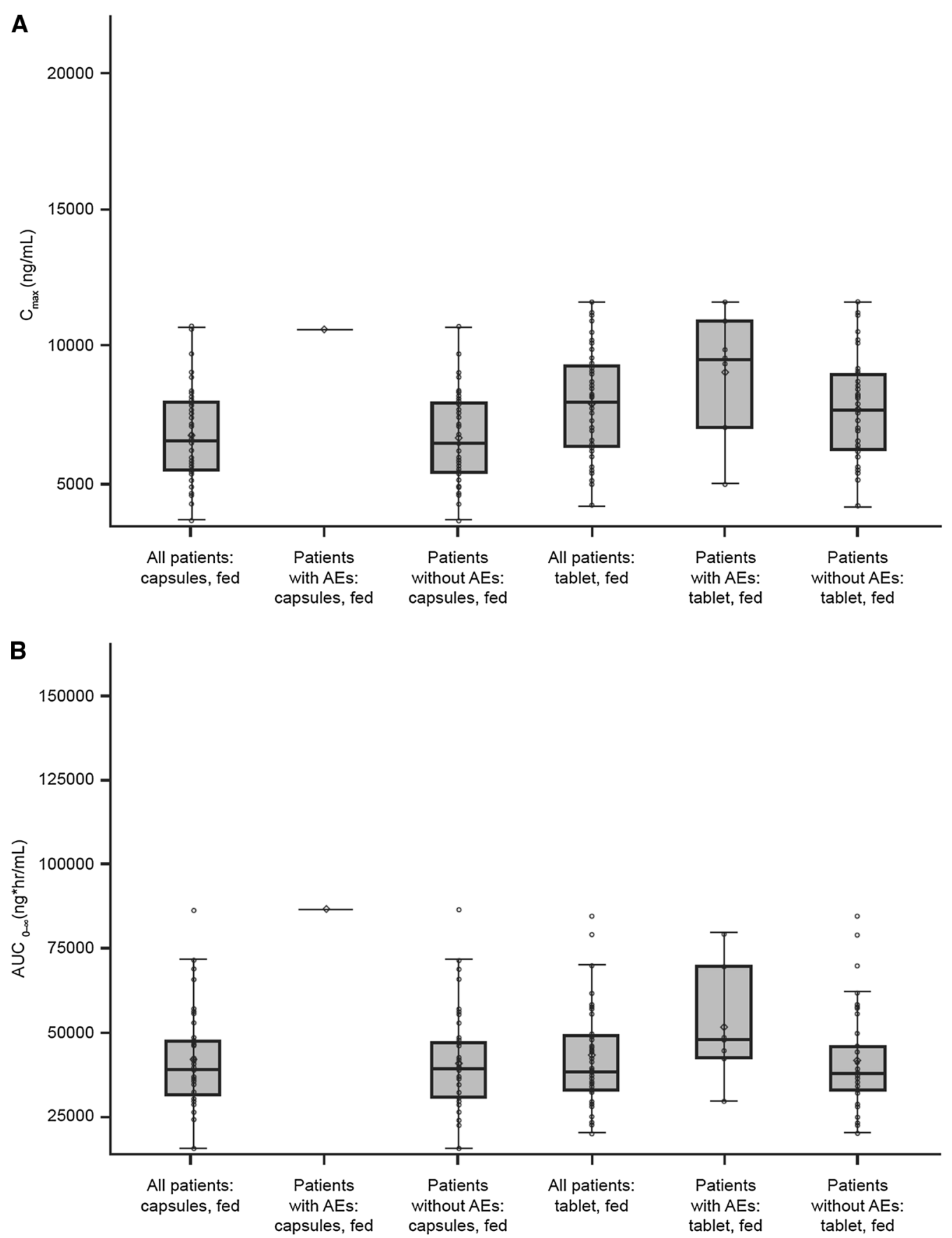

Fig. 3 Distribution of $\mathbf{a} C_{\max }$ and $\mathbf{b} \mathrm{AUC}_{0-\infty}$ in the fed treatment period by subjects with and without AEs. Box and whisker plot defines the interquartile range; center line is the median; symbol is the mean; whiskers are the upper and lower limits of 1.5 times the interquartile range.
Each subject is presented once within each treatment, for all subjects and by $\mathrm{AE}$, reported or not. $A E$ adverse event, $A U C_{0-\infty}$, area under the plasma concentration versus time curve from time zero to infinity, $C_{\max }$ peak plasma concentration 


\section{Safety}

A total of $22(50.0 \%)$ subjects experienced at least one AE during the study. All AEs were rated as mild, and no serious AEs, deaths or AEs of special interest (cases of potential drug-induced liver injury and suspected transmission of an infectious agent by the study drug) were reported.

The most frequently $(\geq 2)$ reported AEs were nausea $[13(29.5 \%)]$, dizziness [8 (18.2\%)], headache [4 (9.1\%)], constipation [4 (9.1\%)], vomiting [2 (4.5\%)] and dyspepsia [2 (4.5\%)] (Table 5). A smaller proportion of subjects experienced AEs in the fed state versus the fasted state for both the tablet [7 (15.9\%) vs. 16 (36.4\%), respectively] and the capsules [1 (2.3\%) vs. $14(31.8 \%)$, respectively]. There was no apparent relationship between drug exposure and AEs based on a graphical examination of the exposure-response relationship (Fig. 3).

\section{DISCUSSION}

The EMA bioequivalence guideline suggests that testing under fasted conditions is more sensitive in detecting differences between formulations than under fed conditions. However, the guidelines also suggest that bioequivalence studies should generally be conducted under fed conditions for products recommended for administration with food [23]. Similarly, the FDA recommends conducting bioequivalence studies under fasting and fed conditions for all orally administered immediate-release drug products [24].

In a previous PK study of the pirfenidone capsule formulation in healthy volunteers, the presence of food was associated with a reduction in $C_{\max }$ value versus the fasted state, which was correlated with a reduction in gastrointestinal AEs [14]. This finding reflects clinical practice, with patients advised to take pirfenidone with or after a meal; therefore, this study also investigated the PK and bioequivalence of the pirfenidone tablet formulation under fed conditions. Consistent with the previous study, our results indicate that the presence of food reduces the rate and extent of pirfenidone absorption from the tablet formulation. A statistically significant reduction in pirfenidone $C_{\max }$ was observed in the fed state versus the fasted state; whereas no statistically significant differences were observed for $\mathrm{AUC}_{0-\mathrm{t}}$ and $\mathrm{AUC}_{0-\infty}$ measurements. The results of this study demonstrate that, in the fasted state, the pirfenidone $1 \times 801-\mathrm{mg}$ tablet is bioequivalent to $3 \times 267-\mathrm{mg}$ capsules. In the fed state, the bioequivalence criteria were met based on $\mathrm{AUC}_{0-\mathrm{t}}$ and $\mathrm{AUC}_{0-\infty}$ measurements, whereas the upper bound of the 90\% CI values for $C_{\max }(125.6 \%)$ was slightly outside the bioequivalence limits (by $0.6 \%$ ).

The higher $C_{\max }$ and shorter median $t_{\max }$ with the tablet formulation compared with the capsules suggest that pirfenidone undergoes faster absorption following administration of the tablet compared with the capsules when food is present. It is possible that release of pirfenidone from the capsule at the site of absorption is delayed following a high-fat meal. One hypothesis is that multiple lighter capsules may float in the fed stomach, whereas a single heavier tablet may sink and mix more readily, ultimately delaying gastric emptying for the more buoyant capsules compared with the tablet [25].

The high-fat meal consumed during this study represented extreme dietary conditions, with subjects consuming approximately 8001000 calories, of which 50\% were from fat. EMA and FDA guidelines recommend conducting fed bioequivalence studies using a high-fat, high-calorie meal to provide the greatest effect on gastrointestinal physiology, thereby a maximum food effect on systemic drug bioavailability could be investigated $[23,24]$. In practice, dietary conditions would likely be intermediate to the fasted and fed states utilized in this study, and, therefore, the $17 \%$ increases in $C_{\max }$ between the tablet and capsule formulations are not expected to have a clinically meaningful impact on the benefit-risk profile of pirfenidone in patients with IPF.

During this study, all AEs were mild, with no discontinuations, serious AEs or deaths reported. The results are consistent with the known safety profile of pirfenidone [4, 5]. Overall, a smaller proportion of subjects experienced AEs in the fed state compared with the fasted state with both the tablet and capsule formulations. The observed food effect on the AE profile is 
consistent with that observed in previous studies for pirfenidone capsules [14], and reinforces the importance of taking pirfenidone with food, as has been noted previously [11]. However, it is notable that, in the fed state, only one AE of hot flush was reported with the capsule. This is in contrast to previous studies of the capsule in the fed state in which more AEs, including nausea and dizziness, were observed [14].

Previous studies suggested that $C_{\max }$ and risk of adverse gastrointestinal events were correlated [14]. In this study, under the fasted state, both formulations had similar incidences of AEs and a similar $C_{\max }$ was observed between the two dosage forms. In the fed state, a greater proportion of subjects experienced AEs with the tablet formulation compared with the capsule formulation. Although $C_{\max }$ was slightly higher with the tablet versus the capsule formulation, there was no apparent relationship between drug exposure and AEs based on a graphical examination of the exposure-response relationship. For the tablet under fed conditions, the mean or median $C_{\max }$ (or $\mathrm{AUC}_{0-\infty}$ ) values for the subjects who experienced AEs were trending higher; however, the overall distribution of individual exposure values for these subjects when compared with the subjects without AEs is similar. Taken together, these observations indicate that the slightly higher $C_{\max }$ observed with the tablet relative to the capsules in the fed state in this study is not expected to have a clinically meaningful impact on safety.

Clinical studies in patients with IPF have shown that pirfenidone reduces the decline in forced vital capacity and the risk of all-cause mortality versus placebo at 1 year $[9,10]$. However, IPF is a chronic, progressive condition that requires long-term treatment. The simplified dosing regimen offered by the pirfenidone 801-mg tablet formulation may enhance longer-term adherence in patients once they are established on the recommended maintenance dose. Additional dose strengths, including 267and 534-mg tablets, will accommodate the recommended dose titration and flexible dose modification until treatment is stabilized. Assessing the bioequivalence of the highest single dose is in accordance with the EMA and FDA guidelines, which state that it is sufficient to establish bioequivalence with the highest dose $[23,24]$. Therefore, the results from this bioequivalence study, together with in vitro dissolution testing, support a biowaiver request for the 267- and 534-mg strengths of pirfenidone tablets.

Although our study was conducted in accordance with EMA and FDA guidelines on the investigation of bioequivalence $[23,24]$, the limitations of our methodology should be acknowledged. The subjects included in our study were healthy volunteers aged $18-55$ years; however, in clinical practice, IPF is most commonly diagnosed in the seventh or eighth decade of life $[3,26,27]$. Patients with IPF have also been shown to have a high burden of comorbidities and concomitant medication [26, 28]. Therefore, it is possible that the $\mathrm{AE}$ profile observed in our study might not be representative of the real-world setting. However, it should be noted that the safety profile of the pirfenidone capsule formulation has been extensively characterized [29], and no significant differences in safety profile between the capsule and tablet formulation are anticipated.

\section{CONCLUSION}

In conclusion, the results from this study demonstrated bioequivalence between the pirfenidone $1 \times 801-\mathrm{mg}$ tablet and pirfenidone $3 \times 267-\mathrm{mg}$ capsules in the fasted state in healthy adult volunteers. The small difference in $C_{\max }$ between the tablet and the capsules observed in the fed state is not expected to have a clinically meaningful impact on the benefit-risk profile of pirfenidone, while the simplified dosing regimen with tablets may increase adherence to treatment.

\section{ACKNOWLEDGEMENTS}

The authors would like to thank Indiana Strombom, an employee of F. Hoffmann-La Roche Ltd., San Francisco, CA, USA, who was the safety scientific lead for this project. The authors would like to thank Fabian Schwarb and Neil Parrott, employees of F. Hoffmann-La Roche Ltd., Basel, Switzerland, for their invaluable technical and scientific support during the 
development of the pirfenidone tablet formulation. The authors would like to thank David Kardatzke, an employee of F. Hoffmann-La Roche Ltd., San Francisco, CA, USA, for his contribution to the statistical analysis.

Funding. This work was supported by F. Hoffmann-La Roche Ltd. Journal and Open Access fees were provided by F. Hoffmann-La Roche Ltd.

Medical Writing. Medical writing support was provided by Catherine Stanton and Gráinne Faherty on behalf of Complete Medical Communications Ltd, funded by F. Hoffmann-La Roche Ltd.

Authorship. All named authors meet the International Committee of Medical Journal Editors (ICMJE) criteria for authorship for this manuscript, had full access to all of the data in the study, and take responsibility for the work as a whole, including the integrity of the data and accuracy of the data analysis. All named authors have given final approval to the version to be published.

Disclosures. Lin Pan is an employee of Roche-Genentech and holds Roche shares. Paula Belloni is an employee of Roche-Genentech and holds Roche shares. Han Ting Ding is an employee of Roche-Genentech and holds Roche shares. Jianshuang Wang is an employee of Roche-Genentech and holds Roche shares. Wendy S. Putnam is an employee of Roche-Genentech and holds Roche shares. Christopher M. Rubino is a consultant to Roche-Genentech, and Executive Vice President of Pharmacometrics at the Institute of Clinical Pharmacodynamics, which had previously received grant funding from InterMune (now Roche). Lin Pan: Contributed to study design, interpretation of PK results, and authoring of CSR. Paula Belloni: Contributed to the review and interpretation of the PK and safety data. Han Ting Ding: Contributed to the analysis of PK and bioequivalence data. Jianshuang Wang: Contributed to the bioanalytical method validation and PK sample analysis. Christopher M. Rubino: Contributed to the design of the study/analysis methods and the interpretation of the results. Wendy S. Putnam: Contributed to study design, interpretation of PK results, and authoring of CSR.
Compliance with Ethics Guidelines. All procedures followed were in accordance with the ethical standards of the responsible committee on human experimentation (institutional and national) and with the Helsinki Declaration of 1964, as revised in 2013. Informed consent was obtained from all patients for being in the study.

Data Availability. All data generated or analyzed during this study are included in the published article or as supplementary information files.

Open Access. This article is distributed under the terms of the Creative Commons Attribution-NonCommercial 4.0 International License (http://creativecommons.org/licenses/ by-nc/4.0/), which permits any noncommercial use, distribution, and reproduction in any medium, provided you give appropriate credit to the original author(s) and the source, provide a link to the Creative Commons license, and indicate if changes were made.

\section{REFERENCES}

1. Raghu G, Collard HR, Egan JJ, et al. An official ATS/ ERS/JRS/ALAT statement: idiopathic pulmonary fibrosis: evidence-based guidelines for diagnosis and management. Am J Respir Crit Care Med. 2011;183:788-824.

2. Raghu G, Rochwerg B, Zhang Y, et al. An official ATS/ERS/JRS/ALAT clinical practice guideline: treatment of idiopathic pulmonary fibrosis. An update of the 2011 clinical practice guideline. Am J Respir Crit Care Med. 2015;192:e3-19.

3. Ley B, Collard HR, King TE Jr. Clinical course and prediction of survival in idiopathic pulmonary fibrosis. Am J Respir Crit Care Med. 2011;183:431-40.

4. Food and drug administration. Highlights of prescribing information Esbriet. https://www. accessdata.fda.gov/drugsatfda_docs/label/2017/208 780s000lbl.pdf. Accessed 1 June 2017.

5. European Medicines Agency. Summary of product characteristics: Esbriet. http://www.ema.europa. eu/docs/en_GB/document_library/EPAR_-_Product_ 
Information/human/002154/WC500103049.pdf. Accessed 1 June 2017.

6. Schaefer CJ, Ruhrmund DW, Pan L, Seiwert SD, Kossen K. Antifibrotic activities of pirfenidone in animal models. Eur Respir Rev. 2011;20:85-97.

7. Didiasova M, Singh R, Wilhelm J, et al. Pirfenidone exerts antifibrotic effects through inhibition of GLI transcription factors. FASEB J. 2017;31(5):1916-28.

8. Knuppel L, Ishikawa Y, Aichler M et al. A novel antifibrotic mechanism of nintedanib and pirfenidone: inhibition of collagen fibril assembly. Am J Respir Cell Mol Biol. 2017;57(1):77-90.

9. King TE Jr, Bradford WZ, Castro-Bernardini S, et al. A phase 3 trial of pirfenidone in patients with idiopathic pulmonary fibrosis. $\mathrm{N}$ Engl J Med. 2014;370:2083-92.

10. Noble PW, Albera C, Bradford WZ, et al. Pirfenidone for idiopathic pulmonary fibrosis: analysis of pooled data from three multinational phase 3 trials. Eur Respir J. 2016;47:243-53.

11. Costabel U, Bendstrup E, Cottin V, et al. Pirfenidone in idiopathic pulmonary fibrosis: expert panel discussion on the management of drug-related adverse events. Adv Ther. 2014;31:375-91.

12. Nathan S, Lancaster L, Albera C, et al. Dose modifications and dose intensity during treatment with pirfenidone. Eur Respir J. 2016;48(Suppl 60):OA1764.

13. Hu J, Shang D, Xu X, et al. Effect of grapefruit juice and food on the pharmacokinetics of pirfenidone in healthy Chinese volunteers: a diet-drug interaction study. Xenobiotica. 2016;46:516-21.

14. Rubino CM, Bhavnani SM, Ambrose PG, Forrest A, Loutit JS. Effect of food and antacids on the pharmacokinetics of pirfenidone in older healthy adults. Pulm Pharmacol Ther. 2009;22:279-85.

15. Shi S, Wu J, Chen H, Chen H, Wu J, Zeng F. Singleand multiple-dose pharmacokinetics of pirfenidone, an antifibrotic agent, in healthy Chinese volunteers. J Clin Pharmacol. 2007;47:1268-76.

16. Cramer JA, Roy A, Burrell A, et al. Medication compliance and persistence: terminology and definitions. Value Health. 2008;11:44-7.

17. Bansilal S, Castellano JM, Garrido E, et al. Assessing the impact of medication adherence on long-term cardiovascular outcomes. J Am Coll Cardiol. 2016;68:789-801.

18. Kim S, Shin DW, Yun JM, et al. Medication adherence and the risk of cardiovascular mortality and hospitalization among patients with newly prescribed antihypertensive medications. Hypertension. 2016;67:506-12.

19. Tangkiatkumjai M, Walker DM, Praditpornsilpa K, Boardman H. Association between medication adherence and clinical outcomes in patients with chronic kidney disease: a prospective cohort study. Clin Exp Nephrol. 2016;21(3):504-12.

20. World Health Organization. Adherence to longterm therapies. Evidence for action. http://apps. who.int/iris/bitstream/10665/42682/1/9241545992. pdf. Accessed 15 Mar 2017.

21. Claxton AJ, Cramer J, Pierce C. A systematic review of the associations between dose regimens and medication compliance. Clin Ther. 2001;23:1296-310.

22. Schroeder K, Fahey T, Ebrahim S. How can we improve adherence to blood pressure-lowering medication in ambulatory care? Systematic review of randomized controlled trials. Arch Intern Med. 2004;164:722-32.

23. European Medicines Agency. Guideline on the investigation of bioequivalence. http://www.ema. europa.eu/docs/en_GB/document_library/Scientific guideline/2010/01/WC500070039.pdf. Accessed $1 \overline{5}$ Mar 2017.

24. Food and Drug Administration. Guidance for Industry. Food-effect bioavailability and fed bioequivalence studies. http://www.fda.gov/downloads/ RegulatoryInformation/Guidances/UCM126833.pdf. Accessed 20 Feb 2017.

25. Washington N, Washington C, Wilson C. The stomach. In: Washington N, Washington C, Wilson C, editors. Physiological pharmaceutics: barriers to drug absorption. London: Taylor and Francis; 2001. p. 75-108.

26. Meltzer EB, Noble PW. Idiopathic pulmonary fibrosis. Orphanet J Rare Dis. 2008;3:8.

27. Strand MJ, Sprunger D, Cosgrove GP, et al. Pulmonary function and survival in idiopathic vs secondary usual interstitial pneumonia. Chest. 2014;146:775-85.

28. Wuyts W, Dahlqvist C, Slabbynck H et al. Demographics and healthcare utilization of patients with idiopathic pulmonary fibrosis (IPF) in a real-world setting: updated findings from 277 patients in the PROOF registry. Poster A1127 presented at the ATS 2017, 2017.

29. Lancaster L, Albera C, Bradford WZ, et al. Safety of pirfenidone in patients with idiopathic pulmonary fibrosis: integrated analysis of cumulative data from 5 clinical trials. BMJ Open Respir Res. 2016;3:e000105. 